\title{
Closing Achievement Gaps using the Green-BIM Teaching Method in Con- struction Education Curriculum
}

\section{Prof. Jin-Lee Kim P.E., California State University, Long Beach}

Dr. Jin-Lee Kim, Ph.D., P.E., LEED AP BD+C, USGBC Faculty, is an Associate Professor of the Department of Civil Engineering and Construction Engineering Management at California State University Long Beach. He is a director of Green Building Information Modeling laboratory. His research interests include advanced construction scheduling techniques for optimization, green buildings, building information modeling, cost estimating methods, international construction, project delivery systems, statistical methods for construction engineers, project management practices, and engineering educational research methods. He is an active member of the American Society for Engineering Education and American Society of Civil Engineers, Construction Research Council of Construction Institute, ASCE. 


\title{
Closing Achievement Gaps using the Green-BIM Teaching Method in Construction Education Curriculum
}

\author{
Jin-Lee Kim \\ Department of Civil Engineering \& Construction Engineering Management \\ California State University at Long Beach \\ 1250 Bellflower Blvd., Long Beach, CA 90840 - U.S.A \\ Email: jinlee.kim@csulb.edu
}

\begin{abstract}
:
This paper presents the assessment results from an ongoing NSF TUES project for the Green-BIM teaching method that seeks to deepen the knowledge and skills for BIM technology in order for the construction engineering management students to learn the state-of-art skills and knowledge of sustainability practices. The GreenBIM teaching method developed by the author was used to teach a construction management course offered at California State University Long Beach. The objective of this paper is to assess the effectiveness of the Green-BIM teaching method to examine if the method can close achievement gaps between the majority group and the minority groups by means of different assessment tools. The evaluation results indicated that the Green-BIM teaching method was effective in improving student learning for both the majority and the minority groups while reducing the gap significantly between the two groups. For the further study, this project will focus on the demonstration of how the Green-BIM teaching method affects students, teaching practice, and student learning over time.
\end{abstract}

\section{Introduction}

The architecture/engineering/construction (AEC) industry is accelerating sustainability in built environment. The industry now heavily relies on the integrated sustainable design and construction and computer-aided automated solutions. The integrated and practical sustainable building education is essential nowadays for Construction Engineering Management (CEM) students to meet the challenges and opportunities for future employment. Thus, the need for skilled and knowledgeable project managers must be addressed to survive in a competitive environment. The demands for the two emerging fields of Building Information Modeling (BIM) technology and sustainability in construction education are continuously increasing in the AEC industry. In line with the movement of sustainability in a built environment, BIM is a mainstream, emerging tool in the AEC industry used for design and documentation. BIM is a comprehensive, integrated graphic and alphanumeric database, through which the collaboration among the stakeholders can be effectively achieved. ${ }^{1}$ However, the lack of personnel with BIM skills is a significant constraint retarding use of the technology in the AEC industry. ${ }^{2}$ The demand for specialists in these two emerging fields, which are BIM and green building practices, is increasing tremendously due to the fact that green buildings education, research, and practice issues are becoming driving forces in academia and industry. 
The Green-BIM teaching method developed by the author with the support of the NSF TUES program provides students with building models containing integrated architectural information to implement sustainability practices that goes beyond both conventional 2D solutions using electronic drafting board and 3D modeling for purely visualization purposes. Students are expected to enhance their learning ability of sustainability practices through an innovative virtual approach using BIM. The course taught using the Green-BIM teaching method seeks to deepen the knowledge and skills for BIM technology in order to deliver the state-of-art skills and knowledge of sustainability. As one of the assessment plans, there is a need to assess the impact of the course to determine the degree to which the course has been successful in enhancing student knowledge; enhancing teacher pedagogical skills in BIM technology associated with sustainability; and improving student learning, thus closing the achievement gaps, especially among the ethnicity groups. In order to meet the continuing efforts of the NSF TUES project, the objective of this paper is to assess the effectiveness of the Green-BIM teaching method to examine if we can close achievement gaps between the majority group and the minority groups by means of different assessment tools. The Green-BIM teaching method was used to teach a construction management course offered at California State University Long Beach. An evaluation of the effectiveness of the teaching method was conducted using the survey questionnaire before and after the introduction of the teaching method.

\section{Overview of Green-BIM Teaching Method}

The Green-BIM teaching method integrates sustainability practices into the BIM-based teaching method developed in the previous study ${ }^{3}$ in order to enhance students' ability to visualize the building projects from the foundation to the roof and to understand sustainability in a built environment. Prior to the offering of the class in Fall 2013, the writer realized that the BIMbased teaching approach alone was not very effective to deliver sustainability in a built environment, even though it enhances students' ability to visualize the building projects. ${ }^{4}$ Realizing the problems that students experienced in gaining insights to both visualization of building projects and understanding of sustainability in a built environment, the writer designed a Green-BIM teaching method and utilized it to teach CEM 225 course to foster the enhancement of visualization ability about construction details and quantity takeoff of building projects and better understanding of green building practices. CEM 225 Residential and Light Commercial Construction Practices and Estimating course is a mandatory introductory course in planning, design, and construction of residential and light commercial buildings including materials, equipment, construction and assembly methods, quantity take-off, and building codes and standards. The course objective is to expose the students to the basic knowledge and skills of methods of building construction, which include sitework, foundations, structural framing, floor, roof, and wall systems. This class aims to provide an intensive and interactive hands-on approach to understand residential and light commercial construction practices. Students are provided a specific and detailed description on the approach at the beginning of each semester. During the course of the semester, students should follow the instruction to deliver the assignment given each week so they complete all the assignments within the semester. The method is implemented in the lab as a team assignment. The class is designed to meet the three of the program objectives such as (1) an ability to use the techniques, skills, and construction knowledge to develop appropriate levels of cost estimates necessary for project planning and control, (2) an ability to communicate effectively using oral, written, and graphic communication skills, and (3) an ability 
to function on multi-disciplinary teams. Every semester, 25 to 30 number of CEM students who took the two prerequisites, Construction Drawing and Fundamentals of Construction, take this course so that the consistence of the previous knowledge of students is maintained. It is noteworthy that these two prerequisites do not deal with the necessary information on BIM and green building practices. ${ }^{3}$ Students in the course are expected to gain (1) understanding green resources such as building materials, building forms, and building systems, (2) hands-on experience with BIM, especially 3D geometric models instead of 2D CAD designs, and (3) hands-on experience with the effect of green resources on the projects using BIM analysis tools. Students are expected to build strong foundations for understanding global environmental problems such as climate change and ozone depletion, being familiar with the concept of building assessment, gaining a clear understanding about sustainable development and sustainable construction, and help students understand the relationships between sustainability practices and building materials, building forms, and building systems, using BIM technology. The visualization approach using BIM will enable students to implement high-performance green building strategies to explore how the buildings would be "greened."3

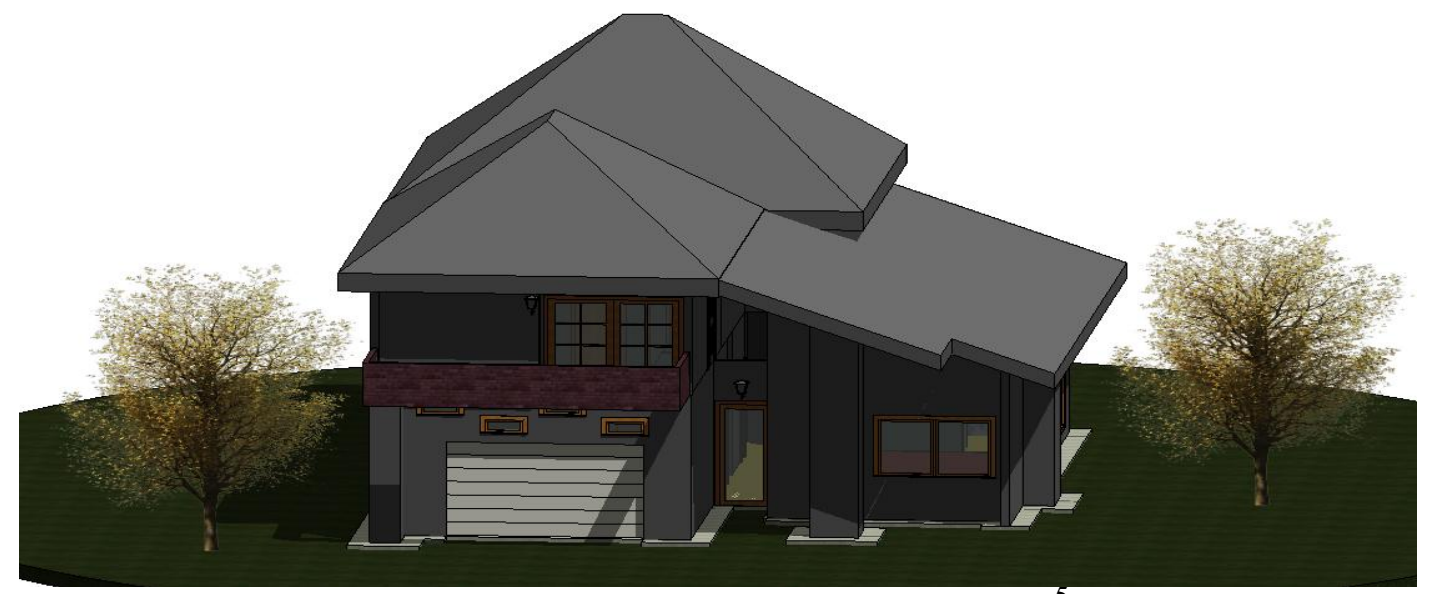

Figure 1. BIM Model used for Instruction ${ }^{5}$

The Green-BIM teaching method starts with the BIM-based teaching approach. Figure 1 shows the BIM model used for the instruction in CEM 225 course in Spring 2014. The teaching framework for sustainability practices consists of a 16-week laboratory- and project-based course for a 3-hour credit unit. The first five weeks (15 hours) are devoted to the foundations and effects of green resources such as building materials, building forms, and building systems, on the green buildings. The next six weeks (18 hours) are devoted to hands-on laboratory-based work. In the second six weeks, the applications and techniques of BIM technology are studied through experiments that create the BIM model and closely simulate the effects of green resources on the building projects. The last five weeks (15 hours) are devoted to hands-on project-based work to understand the relationships between BIM technology and sustainability practices. In these last weeks, how these two revolutionary movements will change the way the construction business operates and transform traditional processes into new workflows is discussed during the presentation of final class projects, so that green solutions from the beginning of the project can be achieved in the AEC industry. Also, guest lectures on sustainability, BIM technology, ethics, and green markets potential are delivered. ${ }^{4}$ 


\section{Methodology}

The Green-BIM teaching method was used to teach a construction management course offered at the California State University Long Beach. The effectiveness of the Green-BIM teaching method was evaluated to see if we can close achievement gaps between the majority group and the minority groups by means of students' interview and exit survey. Besides the traditional assessment tools such as homework, quizzes, tests, exams, lab reports, oral presentations, and projects, a rubric assessment tool was developed and used to evaluate the overall student achievements with respect to the learning objectives of the course. Once the course of study has been established, the overall expectations are determined through reviewing course-learning objectives, lecture notes, handouts, and materials collected on assessment strategies. To ensure the overall expectations are being met, the performance criteria and evaluation methods should be established for assessment. The evaluation plan determines the degree to which the proposed course has been successful in enhancing student knowledge, enhancing teacher pedagogical skills in BIM technology associated with sustainability practices, and improving student learning, thus closing the achievement gap between the majority group and the minority groups. Table 1 tabulates the measurement rubric in the survey form. The survey asks for information on the students' background with sustainability practices, self reports of their knowledge, and the extent to which students express support for sustainability before they take the course and after they finish the course. The survey includes 10 "course learning objective outcome" items. The questionnaire uses a 5 point scale with the most positive self-evaluation at 5 points and the most negative self-evaluation at 1 point. In Spring 2014, with the approval of the University Institutional Review Board, the author collected the ethnicity data from 27 students who took CEM 225 class and divided the cohort into four major ethnicity groups in order to compare the difference or similarity between the majority group and the minority groups. The ethnicity group considered here includes White, Asian/Pacific islander, Hispanic/Latino, and African American.

Table 1. Self-evaluation Rubric in the Survey Form

\begin{tabular}{|l|l|}
\hline \multicolumn{1}{|c|}{ Course Learning Objective/Outcome } & Rating \\
\hline Objective 1: The concept and philosophy of sustainability and Building Information Modeling & \\
\hline Objective 2: The relationships between sustainability and building materials, building forms, and & \\
building systems. & \\
\hline Objective 3: Use of BIM technology to visualize the buildings and demonstrate 3D Walk-through. & \\
\hline Objective 4: Hands-on experience to determine the quantities of the building materials using BIM & \\
\hline Objective 5: The concept of building assessment such as USGBC green building rating system, & \\
\hline LEED (Leadership in Energy and Environmental Design). & \\
\hline Objective 6: How to resolve the environmental issues that arise from the GHG emissions due to & \\
the building materials and energy use of the buildings. & \\
\hline $\begin{array}{l}\text { Objective 7: A strategy of building green with WOOD by considering the following: } \\
\text { Energy content, construction process, indoor air quality (IAQ), building life cycle, and } \\
\text { preservative-treated wood. }\end{array}$ & \\
\hline $\begin{array}{l}\text { Objective 8: A strategy of building green with MASONRY by considering the following: Energy } \\
\text { usage, cost and fuel consumption of masonry production, and thermal mass effect of natural } \\
\text { heating and cooling strategies such as solar heating and nighttime cooling. }\end{array}$ & \\
\hline $\begin{array}{l}\text { Objective 9: A strategy of building green with CONCRETE by considering the following: } \\
\text { Improvement of quality of concrete, reuse of waste materials, conservation of heating and cooling } \\
\text { energy, and demolition and recycling.. }\end{array}$ & \\
\hline $\begin{array}{l}\text { Objective 10: Development of a BIM model to conduct energy efficiency analysis, structural } \\
\text { analysis, and check California Green Building Code Compliance. }\end{array}$ & \\
\hline
\end{tabular}




\section{Assessments and Results}

This section presents the results on the assessment for the effectiveness of the Green-BIM teaching method evaluated by means of student self-evaluations before and after the semester, respectively. A rubric assessment tool was developed and used to evaluate the overall student achievements with respect to the learning objectives of the course. The student interview and exit surveys have been conducted at the beginning of the semester and at the end of the semester, respectively, in order to measure the impact of the proposed course on students' laboratory practice. Table 2 tabulates descriptive statistics for overall learning outcomes. Figures 2 and 3 illustrate the comparison results among the four ethnicity groups from the interview survey and the exit survey, respectively. As shown in Figure 2, there is a distinct difference between the White group and the rest of groups at the beginning of the semester for all of the objectives, except for the objective 10, which is the development of a BIM model to conduct energy efficiency analysis, structural analysis, and check California Green Building Code compliance. On the other hand, for the exit survey results conducted at the end of the semester, one can find the similar patterns among the groups for all the objectives while the significant improvements have been made before and after the course for all of the objectives, as shown in Figure 3.

Table 2. Descriptive Statistics for Overall Learning Outcomes

\begin{tabular}{|c|c|c|c|c|c|}
\hline Parameter & Variable & White & $\begin{array}{c}\text { Asian/ } \\
\text { Pacific Islander }\end{array}$ & $\begin{array}{l}\text { Hispanic/ } \\
\text { Latino }\end{array}$ & $\begin{array}{c}\text { African } \\
\text { American }\end{array}$ \\
\hline & $\begin{array}{l}\text { No. of } \\
\text { student }\end{array}$ & 10 & 7 & 8 & 2 \\
\hline \multirow[t]{3}{*}{ Before Survey } & Mean & 2.42 & 1.83 & 1.64 & 1.65 \\
\hline & SE Mean & 0.31 & 0.17 & 0.25 & 0.45 \\
\hline & Std. Dev. & 0.99 & 0.46 & 0.72 & 0.64 \\
\hline \multirow[t]{3}{*}{ After Survey } & Mean & 3.87 & 3.09 & 3.43 & 3.15 \\
\hline & SE Mean & 0.18 & 0.13 & 0.21 & 0.55 \\
\hline & Std. Dev. & 0.57 & 0.34 & 0.58 & 0.78 \\
\hline
\end{tabular}

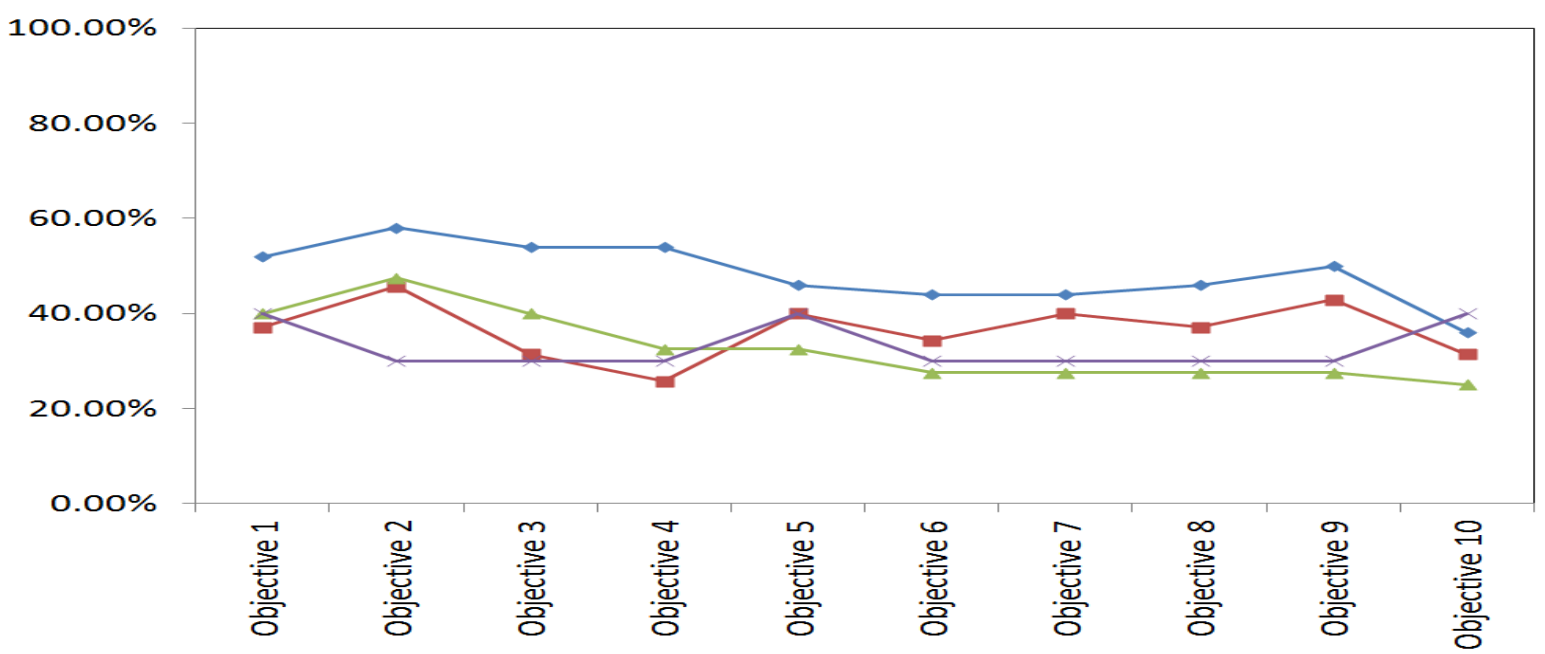

-White - Asian/Pacific Islander - Hispanic or Latino $\rightarrow$ African American

Figure 2. Comparison Results among the Ethnicity Group for Interview Survey 


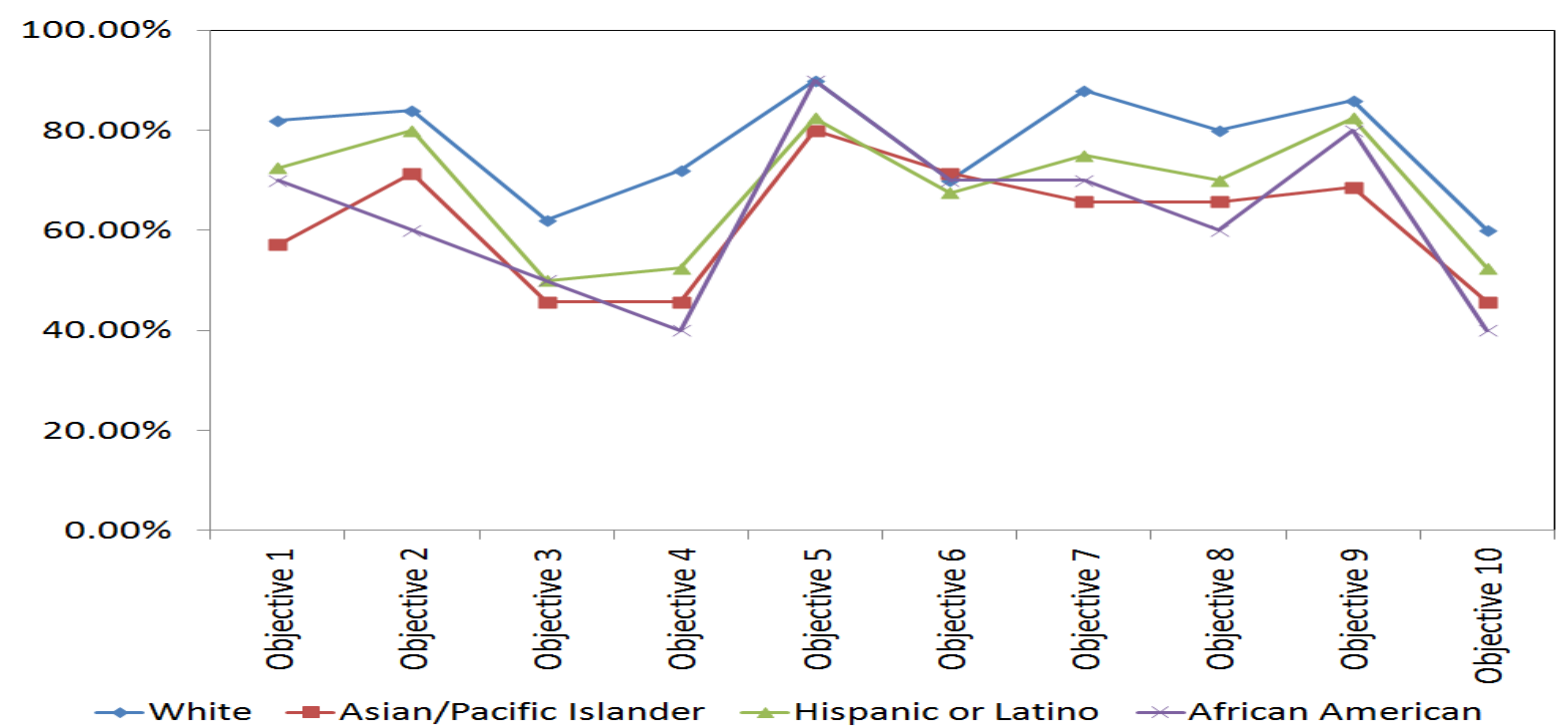

Figure 3. Comparison Results among the Ethnicity Group for Exit Survey

The writer of this paper used an experimental design called a one-way analysis of variance (Oneway ANOVA), which is a technique used to compare means of the four groups using the $\mathrm{F}$ distribution. The purpose of the one-way ANOVA is to compare the mean response rate among four ethnicity groups to see the difference in the students' background with sustainability practices, self reports of their knowledge, and the extent to which students express support for sustainability. The ANOVA tests the null hypothesis that the four ethnicity groups are drawn from populations with the same mean values. We assumed that student response variable residuals are normally distributed or approximately normally distributed, the responses are independent, variances of populations are equal, and responses for a given group are independent and identically distributed normal random variables. ${ }^{6}$ One-way ANOVA provided by using Minitab ${ }^{\circledR} 17$ is used to test whether or not the mean response rates according to the ethnicity group differ. ${ }^{7}$ The null and alternative hypotheses are Ho: $\mu$ White $=\mu$ Asian $=\mu$ Hispanic $=$ $\mu$ African and Ha: at least two means differ. At a 0.05 level of significance, the null hypotheses are rejected because the p-value is much smaller than 0.05 . We have sufficient evidence to show that the null hypothesis is not true.

Table 3 tabulates the one-way ANOVA results for the before survey and the after survey on the students' overall learning outcomes. For the interview survey results conducted at the beginning of the semester, the test statistics, $F=1.77$, have a $p$-value of 0.182 . The $p$-value is the probability of obtaining a test statistic as large as $F$ value, assuming $H o$ is true. Since $p$-value is greater than $\alpha=0.05$, the null hypothesis cannot be rejected. In addition, the Tukey $95 \%$ simultaneous confidence intervals for all pair-wise comparisons among the four ethnicity groups show that the null hypothesis is not rejected because the observed significance level or $p$-value of 0.182 is greater than $\alpha=0.05$. Thus, there is not sufficient evidence to conclude that the true mean response rates differ for at least two of the four groups. However, for the exit survey results conducted at the end of the semester, the test statistics, $F=3.44$, have a $p$-value of 0.037 . The $p$ value is the probability of obtaining a test statistic as large as $F$ value, assuming $H o$ is true. Since 
$p$-value is less than $\alpha=0.05$, the null hypothesis is rejected. In addition, the Tukey $95 \%$ simultaneous confidence intervals for all pair-wise comparisons among the four ethnicity groups show that the null hypothesis is rejected because the observed significance level or $p$-value of 0.037 is less than $\alpha=0.05$. Thus, there is sufficient evidence to conclude that the true mean response rates differ for at least two of the four groups. Therefore, it can be concluded that there is a statistically significant difference among the groups after the introduction of the Green-BIM teaching method. The results suggest that there be a further analysis needed to examine in what degree the gap among the four ethnicity groups in terms of self-evaluation is reduced.

Table 3. One-way ANOVA Results for Overall Learning Outcomes

\begin{tabular}{clccccc}
\hline Parameter & Source & DF & Adj SS & Adj MS & F-value & p-value \\
\hline Before Survey & Factor & 3 & 3.25 & 1.08 & 1.77 & 0.182 \\
& Error & 23 & 14.11 & 0.61 & & \\
& Total & 26 & 17.37 & & & \\
After Survey & & & & & & \\
& Factor & 3 & 2.85 & 0.95 & 3.34 & 0.037 \\
& Error & 23 & 6.55 & 0.28 & & \\
& Total & 26 & 9.40 & & & \\
\hline
\end{tabular}

In addition, pair-wise comparisons using the Tukey procedure are employed to compare each performance measure means with each of the other measure means. The parameters of interest are all pair-wise differences among the performance measure means. The pair-wise comparison aims to detect significant inequalities for all performance measure means. ${ }^{8}$ The parameter of interest is the difference among the response means of the four groups. The response scores in each group were compared with the assumption that the students expressed their best selfevaluation results. For the interview survey results conducted at the beginning of the semester, Tukey $95 \%$ simultaneous confidence intervals for all pair-wise comparisons among the four ethnicity groups show that the null hypothesis is not rejected because means among the groups share a same letter, which means then are not significantly different. On the other hand, for the exit survey results conducted at the end of the semester, Tukey $95 \%$ simultaneous confidence intervals for all pair-wise comparisons among the four ethnicity groups show that the null hypothesis is rejected because means among the groups do not share a same letter, which means then are significantly different. Thus, there is sufficient evidence to conclude that the true mean response rates differ for at least two of the four ethnicity groups.

\section{Conclusions}

This paper presented the comparative analysis using data collected for the ongoing NSF project to examine if the Green-BIM teaching method is effective in improving student learning for both the majority and the minority groups while reducing the gap significantly between the two groups. The comparison results between the two groups reveal that the Green-BIM teaching method helps them learn and understand better sustainability in a built environment and reduce the gap between the two groups over the study period of the NSF TUES project. For the further study, this project will focus on the demonstration of how the proposed course affects students, teaching practice, and student learning over time. The cohort design will allow us to see how groups of students who receive multiple years of exposure to sustainability grow and deepen in 
their understanding of sustainability and how to improve BIM skills. The challenge in evaluating an intervention using a quasi-experimental design is in managing a non-random sample and analyzing the data to allow for causal inference to be made from the findings.

\section{Acknowledgment}

This material is based upon work supported by the National Science Foundation under Grant No. DUE-1140941. Any opinions, findings, and conclusions or recommendations expressed in this material are those of the author and do not necessarily reflect the views of the National Science Foundation.

\section{References}

1. Davis, K. A., and Casey Cline, R. (2009). "Improving course comprehension through experimental learning." 2009 Construction Research Congress, Seattle, WA, pp. 1409-1418.

2. Berwald, S. (2008). "From CAD to BIM: The experience of architectural education with building information modeling." Proceeding of Architectural Engineering Conference, Sept. 25-27, Denver, CO.

3. Kim, J.-L. (2012). "Use of BIM for effective visualization teaching approach in construction education," Journal of Professional Issues in Engineering Education and Practice, ASCE, Vol. 138, No. 3, pp. 214-223.

4. Kim, J.-L. (2014). "Effectiveness of Green-BIM Teaching Method in Construction Education Curriculum," Proceedings of the 2014 American Society for Engineering Education Annual Conference, June 15-18, 2014, Indianapolis, Indiana, No. 8596.

5. Kim, J.-L., Greene, M., and Kim, S. (2014). "Economic Impact of New Green Building Code on Residential Project Development from Energy Consumption Perspectives,” Journal of Green Building, V9, N4, pp. $105-123$.

6. Kuehl, R. O. 2000. Design of experiment: Statistical principles of research design and analysis. 2nd ed., Duxbury Press, Pacific Grove, CA.

7. Levine, D. M., Ramsey, P. P., and Smidt, R. K. (2001). Applied statistics for engineers and scientists using Microsoft Excel and Minitab, Prentice Hall, Upper Saddle River, NJ.

8. Kim, J.-L., and Cheung, S. L. (2011). "Evaluation of Green Project Rating System for New Construction Projects," Proceedings of the 2011 International Conference on Sustainable Design and Construction, March 23-25, 2011, Kansas City, MO, pp. 360-367.

\section{Author Biographies}

Dr. Jin-Lee Kim, Ph.D., P.E., LEED AP BD+C, USGBC Faculty, is an Associate Professor of the Department of Civil Engineering and Construction Engineering Management at California State University Long Beach. He is a director of Green Building Information Modeling laboratory. His research interests include advanced construction scheduling techniques for optimization, green buildings, building information modeling, cost estimating methods, international construction, project delivery systems, statistical methods for construction engineers, project management practices, and engineering educational research methods. He is an active member of the American Society for Engineering Education and American Society of Civil Engineers, Construction Research Council of Construction Institute, ASCE. 